\title{
In honor of Professor Samuel J. Danishefsky
}

\author{
Masayuki Inoue $\mathbb{D}^{1} \cdot$ Dirk Trauner $\mathbb{D}^{2}$
}

Received: 22 March 2019 / Accepted: 22 March 2019 / Published online: 27 May 2019

(c) The Author(s), under exclusive licence to the Japan Antibiotics Research Association 2019

It is our great pleasure and honor to present this special issue of The Journal of Antibiotics dedicated to Professor Samuel J. Danishefsky.

Professor Danishefsky's achievements in Organic Chemistry and Chemical Biology are unparalleled. They include ground-breaking contributions to synthetic methodology (such as the Danishefsky-Kitahara diene, the glycal assembly, or the radical desulfurization of cysteines), the synthesis of hundreds of natural products, and his seminal work on anticancer vaccines and glycoproteins. His routes to complex target molecules, many of which he became aware of in The Journal of Antibiotics, have been as elegant and idiosyncratic as the language he chose to describe them. His work has paved the way for future advancements in organic chemistry and will continue to influence our thinking on strategy and tactics in organic synthesis.

Professor Danishefsky has trained many generations of chemists who were shaped by "Sam", both as scientists and as human beings. This was apparent in a recent memento book, compiled on the occasion of his $80^{\text {th }}$ birthday, which contained hundreds of photos, molecules, and "Samisms".
One of our favorite quotes embodies his brilliant achievements in total synthesis:

"To say this work [the total synthesis of a complex natural product] isn't turning up anything only comes from someone who says surgery is surgery, so removing a corn on a toe is the same as an organ transplant."

Professor Danishefsky has operated successfully on some of the most complex and challenging molecules and has transplanted his philosophy into the minds of many students and colleagues in the chemical community. More than twenty of them have contributed to this special issue. We are excited to share their papers honoring "Sam", to whom we dedicate this issue with admiration and gratitude.

Publisher's note: Springer Nature remains neutral with regard to jurisdictional claims in published maps and institutional affiliations.

\section{Reference}

1. Service RF. Race for molecular summits. Science. 1999;285:184-5.
Masayuki Inoue

inoue@mol.f.u-tokyo.ac.jp

$\triangle$ Dirk Trauner

dirktrauner@nyu.edu

1 Graduate School of Pharmaceutical Sciences, The University of Tokyo, Tokyo, Japan

2 Department of Chemistry, New York University, New York, USA 